\title{
ABORDAREA OPERAȚIONALĂ A FORȚELOR TERESTRE ÎN CONTEXT HIBRID
}

\author{
OPERATIONAL APPROACH OF LAND FORCES \\ IN THE HIBRID CONTEXT
}

\author{
Lt.col.conf.univ.dr. Paul TUDORACHE*
}

\begin{abstract}
Vizualizând diferitele contexte operaționale ale angajării recente a Forțelor Terestre, nu puține au fost situațiile în care structurile nominalizate s-au confruntat și cu adversari neconvenționali, cu toate că, inițial, natura operației fusese definită ca având o nuanță convențională. Această particularitate se perpetuează tot mai agresiv, determinând structurile convenționale ale Forțelor Terestre să opereze pentru a face față atât forțelor regulate, cât și celor neregulate, chiar și în cadrul aceleiași AO. Pe aceste coordonate, articolul are ca scop identificarea principiilor necesare ajustării abordării operaționale a Forțelor Terestre, astfel încât structurile organice să poată performa în angajarea adversarului din AOs în cadrul operațiilor curente și viitoare. De asemenea, un alt obiectiv subsidiar cercetării de față constă în identificarea mutațiilor la nivelul ACOAs, pe baza cărora se va realiza ajustarea FFCOAs.
\end{abstract}

Visualizing the various operational contexts of recent Land Forces' employment, there were many situations where the nominated structures also faced unconventional adversaries, even though, initially, the nature of operation had been identified as having a conventional pattern. This particularity is perpetuated more and more aggressively, determining the conventional military structures of the Land Forces to operate in order to face both regular and irregular forces, even within the same AO. Based on these coordinates, the article triggers to identify the principles needed to adjust the operational approach of Land Forces, so that the organic structures can perform in engaging the adversary from AOs within current and future operations. Also, a subsidiary objective of the present research is to identify the mutations at the level of ACOAs based on which the adjustment of FFCOAs will be made.

Cuvinte-cheie: abordare operațională hibridizată; ACOA, FFCOA; forțe regulate; forțe neregulate.

Keywords: hybrid operational approach; ACOA, FFCOA; regular forces; irregular forces.

Diferitele contexte operaționale recente au scos în evidență faptul că abordările participanților la acțiuni militare au suferit mutații semnificative, cele mai concludente localizându-se la nivelul cursurilor de acțiune (Courses of Action - COA) adoptate. $\mathrm{Nu}$ este atât de dificil de înțeles cum și de ce s-a ajuns la această formulă, justificarea constând în intenția adversarului de a echilibra puterea de luptă prin diminuarea avantajelor convenționale ale forțelor proprii. Practic, forțele proprii sunt nevoite să reacționeze la schimbările operaționale permanente ale adversarului, acesta din urmă fiind în măsură să coreleze ingenios acțiuni ale forțelor regulate și neregulate, chiar și în contextul aceleiași zone de operații (Area of Operations - AO) tactice.

\section{*Academia Forțelor Terestre „Nicolae Bălcescu”, Sibiu \\ e-mail: tudorache.paul@armyacademy.ro}

Reacția forțelor proprii nu a întârziat să apară, iar în acest sens, doctrinele diferitelor armate, din dorința perfecționării pregătirii Forțelor Terestre, întrebuințează forța de opoziție (Opposing Force - OPFOR), clarificând-o teoretic ca „un amestec plauzibil, flexibil și liber în gândire al forțelor regulate, neregulate și/sau elemente ale crimei organizate, reprezentând un compozit de capabilităţi diferite ... (doctrină, tactică, organizare și echipament)" Organizată și pregătită să acţioneze respectând modelul doctrinar al adversarului, utilitatea OPFOR este dată de posibilitatea înțelegerii și combaterii tacticilor, tehnicilor şi procedurilor (Tactics, Techniques, Procedures - TTP) caracteristice adversarului, dezvoltând și aplicând COA adverse (Adversary Courses of Action - ACOA), pe baza hibridizării acțiunilor acestuia.

Din perspectiva abordării operaţionale, Forțele Terestre sunt nevoite să-și regândească opțiunile, fie operând individual, ceea ce presupune o 
adaptare operațională proprie, fie interagenții, în strânsă cooperare cu alte entități de profil, cum sunt forțele pentru operații speciale (Special Operations Forces - SOF).

\section{Mutații la nivelul COA și TTP-urilor adversarului}

În general, ACOAs se determină în baza derulării pregătirii informative a spațiului de luptă (Intelligence Preparation of the Battlefield - IPB), care, conform APP-28, este redenumită sub forma pregătirii informative a mediului operational (Intelligence Preparation of the Operational Environment - IPOE), reprezentând „procesul sistematic de analiză a adversarului (inamicului), terenului și vremii în zona de interes pentru a determina efectele probabile ale acestora asupra operatiiilor"’2. $\mathrm{Cu}$ toate că aceste două concepte diferă, IPB axându-se pe o analiză mai detaliată a elementelor specifice, în timp ce IPOE le abordează mai cuprinzător și mai generic, sprijinind comandantul în ,identificarea intenţiei și COA probabile ... strategiei, vulnerabilităţilor și centrelor de greutate ale adversarului" , în esență, ambele cuprind aceleași activități, astfel: „,definirea mediului operațional, descrierea efectelor mediului asupra operațiilor, evaluarea amenințării, determinarea COAs"4.

Prin urmare, la nivelul vizualizării adversarului, mutaţiile cele mai concludente apar în evaluarea amenințării, respectiv determinarea ACOAs. Prima variabilă, evaluarea amenințării, se axează pe „determinarea capabilităţilor forței de amenințare și principiile doctrinare, respectiv TTPurile pe care aceasta preferă să le întrebuințeze"5. Analiza evaluării amenințării scoate în evidență faptul că, până nu demult, personalul specializat în intelligence din cadrul Forțelor Terestre (S2, G2) lua în considerare doar componenta convențională a adversarului, omițând oarecum corelarea acestora cu capabilitățile și TTP-urile neconvenționale. Drept urmare, în momentul de față, evaluarea amenințării de către S2/G2 ar trebui să fie mult mai cuprinzătoare, incluzând ${ }^{6}$ :

- amenințările regulate - intenții ostile probabile ale forțelor convenționale ale adversarului, cum sunt structurile militare tactice (batalion, brigadă etc.) care dispun de abilitatea de a opera de o manieră multidomeniu; de regulă, forțele convenționale ale adversarului sunt întrebuințate atunci când se creează ferestre de oportunitate, cu alte cuvinte, momente în care forțele convenționale proprii pot fi surprinse;

- amenințările neregulate - intenții ostile probabile ale structurilor teroriste/insurgente, organizaţiilor criminale transnaționale, entități naționaliste, elemente de gherilă, structuri paramilitare etc. care manifestă un grad excesiv de volatilitate în întrebuințarea capabilităților și TTP-urilor specifice;

- amenințările hibride - intenții ostile probabile, fundamentate prin corelarea forțelor convenționale cu cele neconvenționale pentru generarea unor efecte și atingerea unor stări finale comune; de regulă, pe timpul operației, structurile și entitățile caracteristice se completează reciproc pe timpul operației.

Astfel, definirea modelului doctrinar al adversarului de către personalul S2/G2 ar trebui să surprindă tot melanjul de forțe și structuri ale acestuia, începând de la cele convenționale până la cele de ordin neconventional.

În ceea ce privește determinarea ACOAs, aceasta se fundamentează integrând evaluarea amenințării și dezvoltarea graficului/matricei evenimentelor. Prin urmare, ajustarea evaluării amenințării care, după cum s-a subliniat mai sus, reprezintă un element esențial, se transpune obligatoriu și asupra determinării ACOAs. Mai specific, în formă finală, ACOAs trebuie să evidențieze foarte clar capabilităţile, intențiile și acțiunile probabile ale tuturor entităţilor implicate, chiar dacă personalul S2/G2 ar putea întâmpina dificultăți în analizarea și estimarea forțelor neregulate. Există două posibilităţi pentru transpunerea tuturor elementelor adversarului: dezvoltând ACOAs integratoare care să evidențieze toate capabilitățile și acţiunile probabile ale adversarului; dezvoltând ACOAs dedicate componentei convenționale și ACOAs specifice celei neconvenționale. $\mathrm{Cu}$ toate că prima variantă este mult mai complexă și solicitantă, beneficiile aplicării acesteia pot fi mai concludente, deoarece se poate vizualiza mult mai ușor efectele conjugate probabile asupra COAs specifice forțelor proprii (Friendly Forces Courses of Action - FFCOA).

De asemenea, un alt pattern care ar trebui luat în seamă în determinarea ACOAs este cel al conjugării procedeelor operaționale specifice forțelor convenționale, cum sunt apărarea în zonă, 
ofensiva deliberată și așa mai departe, cu TTPuri caracteristice forțelor neregulate. Un astfel de ACOA care respectă oarecum patternul de mai sus este cel întrebuințat de Statul Islamic din Irak și Levant (Islamic State of Iraq and Syria - ISIL) pentru apărarea oraşului Mosul, determinat, la acea vreme, ca centru de greutate (Center of Gravity $C O G)$ al forțelor ISIS în Irak. În linii mari, COA ISIS s-a bazat pe adoptarea procedeului apărării în zonă, alimentat de TTP-uri hibride, manifestate sub forma: integrării în dispozitivul de luptă a orașului Mosul; folosirii populației indigene (sechestrată de jihadiști) ca scut uman; amplasării, pe principalele căi de apropiere, a întregii game de dispozitive explozive improvizate (Improvised Explosive Device - IED), majoritatea dintre acestea dispuse în mașini capcană (Vehicle-Borne Improvised Explosive Device - VBIED) pentru realizarea contramobilității forțelor proprii ${ }^{7}$.

Concluzionând asupra acestei prime părți, se poate aprecia faptul că adversarul nu mai trebuie interpretat divizat, ci mai degrabă de o manieră integratoare care să surprindă toate elementele generării puterii de luptă adverse, pe de o parte, respectiv intențiile probabile privind direcționarea acesteia, pe de altă parte.

\section{Principii privind hibridizarea COA specifice forțelor proprii}

Clarificând aspectele legate de reconfigurarea ACOAs, în continuare atenţia va fi îndreptată asupra analizării abordării operaționale a Forțelor Terestre, pentru a identifica acele elemente care solicită intervenții în cadrul acesteia.
În primul rând, apelând la literatura militară de specialitate, prin abordare operațională se înțelege „o descriere generică a misiunii, conceptelor operaționale, sarcinilor și acțiunilor necesare îndeplinirii misiunii"”. Dintr-o altă perspectivă teoretică, abordarea operațională reprezintă capul de pod care leagă starea inițială și starea finală dorită, asigurând depășirea obstacolelor identificate, care sunt reprezentate de ACOAs (Figura 1).

Identificarea răspunsului la întrebarea asociată abordării operaționale solicită analizarea problematiciidezvoltăriiFFCOAs specifice Forțelor Terestre, astfel spus cum ar trebui ajustate astfel încât să asigure depășirea ACOAs. Reprezentând „orice secvențiere a activităților pe care un individ sau o unitate o poate urma ... o schemă dezvoltată pentru îndeplinirea unei misiuni", , FFCOAs, odată ce au fost dezvoltate și aprobate, trebuie să fie în măsură să ,înfrângă toate COA fezabile ale inamicului (adversarului), în timp ce contabilizează toate activitățile tactice" ${ }^{10}$.

Operaționalizând conceptul esențial cercetării de față, abordarea operațională hibridizată poate fi definită ca o modalitate de depășire a ACOAs, corelândmisiunileșisarcinile desfășurateînspectrul convențional, neconvențional și/sau hibrid de către structurile organice dedicate, în scopul creării condițiilor estimate în cadrul stării finale dorite. Dincolo de suportul operațional multidomeniu, axându-ne doar pe acțiunea structurilor de manevră în AO, depășirea ACOAs de către Forțele Terestre se poate realiza astfel:

- independent - este mai costisitoare, deoarece implică pregătirea prealabilă a structurilor dedicate

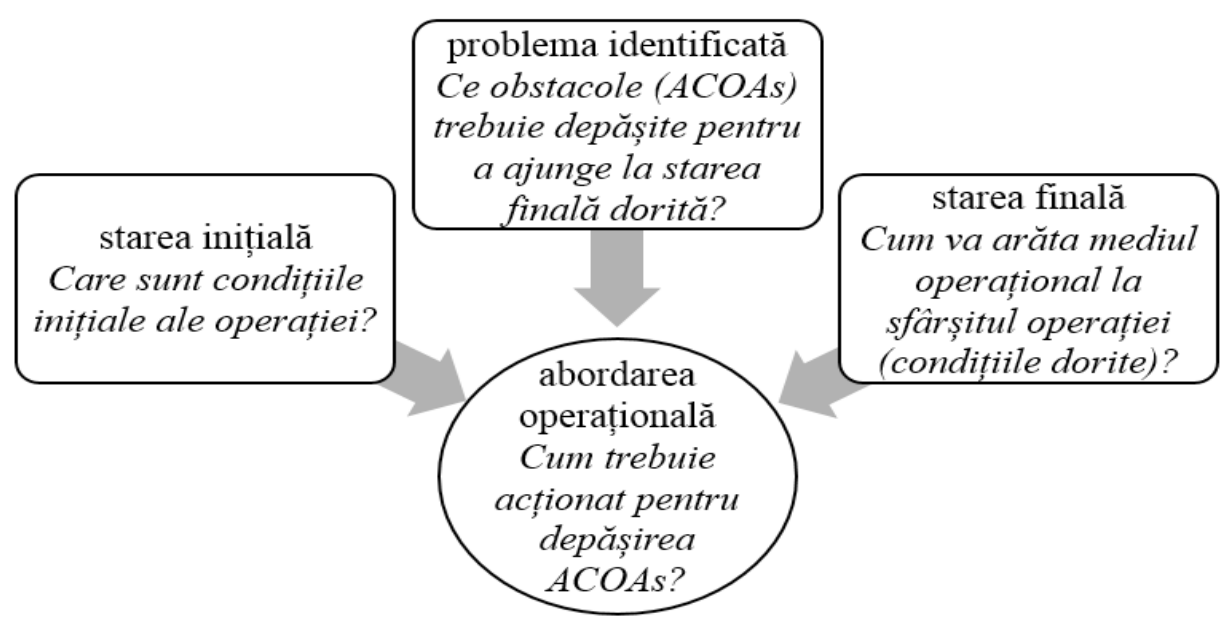

Figura 1 Abordarea operațională în cadrul Forțelor Terestre (Concepția autorului) 
pentru contracararea acțiunilor neconvenționale sau hibride;

- în cooperare cu elemente SOF - presupune divizarea responsabilităților, structurilor Forțelor Terestre revenindu-le angajarea componentei convenționale din cadrul ACOA, în timp ce SOF va asigura efectele dorite, acționând asupra componentei neconvenționale;

- în cooperare cu alte elemente cu rol în realizarea manevrei forțelor luptătoare.

Astfel, o constantă relativ nouă care trebuie introdusă în ecuaţia abordării operaționale este cea a angajării componentei neconvenționale a adversarului, soluția cea mai la îndemână constând în întrebuinţarea SOF (Figura 2).

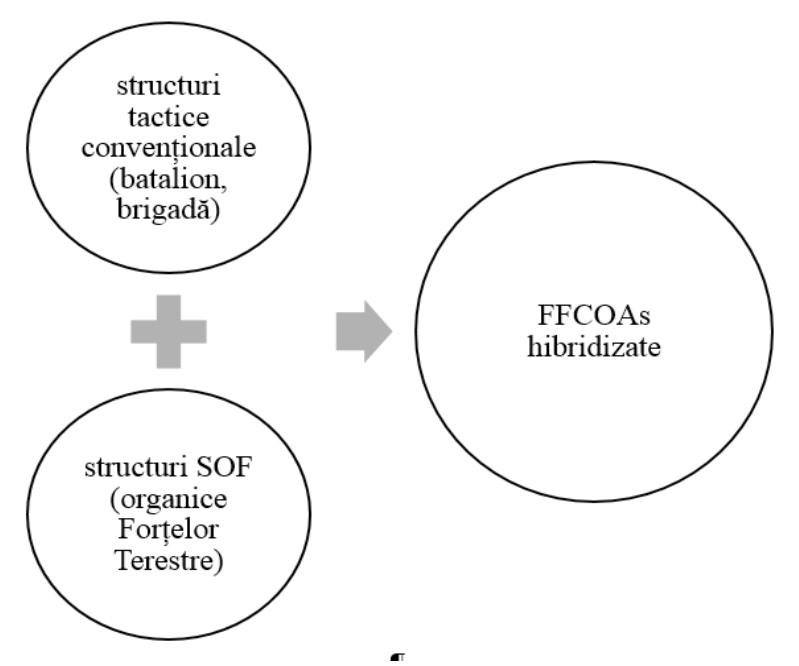

Figura 2 Hibridizarea FFCOAs specifice Forțelor Terestre - structuri tactice luptătoare

(Concepția autorului)

Structurile SOF pot fi parte organică din cadrul categoriei Forțelor Terestre, așa cum este modelul american (Army Special Operations Forces $A R S O F)$, sau categorie separată de forțe, după modelul altor armate. Pentru înlesnirea exercitării comenzii și controlului (Command and Control C2) și pentru dezvoltarea coeziunii operaționale, ar fi mai indicată prima variată (SOF organice), în timp ce SOF, ca și categorie separată, este pretabilă unor obiective de importanță operativă sau strategică. În configurația de mai sus, SOF va dispune de ,abilitatea de a opera în echipe de nivel mic, în medii prietenoase, politic sensibile și incerte sau ostile ... unilateral sau cu, respectiv, prin intermediul forțelor și populațiilor indigene" ${ }^{11}$. Alături de acțiunile letale consacrate, $\mathrm{SOF}$ va susține structurile Forțelor Terestre $\mathrm{cu}$ acțiuni nonletale, urmărind modelarea forțelor de securitate locale și câștigarea sprijinului populației locale.

În cadrul abordării operaționale hibride a Forțelor Terestre, gama misiunilor și sarcinilor componentei SOF este definită de ${ }^{12}$ :

- război neconvențional - crearea/susținerea mișcării de rezistență, insurgenței, acționând prin intermediul sau cu forțe auxiliare ascunse sau de tip gherilă;

- contrainsurgență - combaterea elementelor insurgente din AO; pentru economia acestei misiuni, o variabilă esenţială constă în atragerea populaţiei indigene;

- contraterorism - combaterea elementelor teroriste și infrastructurii acestora, întrebuințând mijloace ascunse, clandestine sau cu vizibilitate redusă;

- asistența forțelor de securitate - susținerea forțelor de securitate locale/regionale din AO în vederea conturării acțiunii unificate a Forțelor Terestre;

- acțiunea directă - „lovituri de scurtă durată și alte acțiuni ofensive la scară redusă, conduse cu capabilităţi militare speciale pentru a cuceri, a distruge, a captura, a exploata, a recupera sau a afecta țintele stabilite în medii ostile, interzise ..."13;

- recunoașterile speciale - activități de informații, de supraveghere și de cercetare (Intelligence, Surveillance, Reconnaissance - ISR) în medii ostile, interzise, necesitând capabilităţi militare specializate;

- operații de sprijin informațional - de regulă, operații psihologice (Psychological Operations PSYOPS) desfãșurate în AO;

- operații în domeniul cooperării civili-militari (Civil-Military Cooperation - CIMIC) - angajarea populației indigene și a autorităţilor locale pentru crearea efectelor nonletale;

- pregătirea mediului operațional - activități necesare modelării AO pentru desfășurarea operațiilor viitoare; de regulă, sunt de natură informațională și de securitate;

- căutare, salvare și recuperare - activități cu caracter ofensiv, adoptate pentru a preveni, a descuraja, a anticipa și a răspunde la amenințări/ acte teroriste care includ eliberarea ostaticilor, precum și restabilirea controlului capabilităților și infrastructurii militare și civile.

Îndeplinirea oportună și eficace a misiunilor și sarcinilor de mai sus de către SOF organice 
va alimenta Forțele Terestre cu abilitatea lovirii performante a elementele neconvenționale ale adversarului. Conjugarea acesteia cu acţiunea structurilormilitare convenționale (batalion, brigadă etc.) va coagula capacitatea Forțelor Terestre de a angaja simultan/succesiv toate elementele și capabilitățile specifice ACOAs, asigurând în final realizarea tuturor condițiilor stării finale dorite.

\section{Concluzii}

Forțele Terestre, în fața schimbărilor care țin de reconfigurarea și adaptarea continuă a adversarului la nivelul forțelor regulate, forțelor neregulate sau mixturii acestora, sunt nevoite să identifice acele strategii operaționale a căror aplicabilitate să le garanteze succesul. Clarificând tipologia ACOAs, în momentul de față pot fi definite următoarele variante:

- convențional - modelat de utilizarea structurilor regulate ale adversarului, având $o$ probabilitate de întrebuințare destul de redusă șifiind aplicat, în principiu, în scopuri de descurajare;

- neconvenţional - configurat prin integrarea elementelor neregulate, cum sunt cele teroriste, insurgente, de gherilă, crimă organizată, mișcări de rezistență etc.; având o probabilitate de întrebuințare medie către ridicată, poate avea sens în situații în care puterea de luptă a forțelor proprii este superioară, adversarul căutând să diminueze avantajele operaționale create;

- hibrid - coagulat prin melanjul elementelor regulate și neregulate, în cadrul căruia pot fi identificate următoarele configurații esențiale: accentuat convențional - diminuat neconvențional (probabilitate mică către medie); moderat convențional - moderat neconvențional (probabilitate medie); diminuat convențional - accentuat neconvențional (probabilitate ridicată).

Dintre toate acestea, provocările cele mai solicitante pentru structurile Forțelor Terestre sunt generate de acele ACOAs configurate prin hibridizarea elementelor regulate și neregulate, întrebuințarea acestora având ca scop inițial surprinderea forțelor proprii.

$\mathrm{O}$ astfel de variantă a configurării adversarului necesită a fi soluţionată printr-o abordare operațională similară, altfel spus tot hibridizată (FFCOAs hibride). La nivelul Forțelor Terestre, o soluție pretabilă și poate cea mai recomandată constă în dezvoltarea, în cadrul structurii organice acestora, a unei componente SOF, care, dispunând de capabilitate operațională totală (Fully Operational Capability - FOC), va dispune de abilitatea angajării țintelor neconvenționale atât letal, cât și nonletal.

În încheiere, se poate concluziona faptul că Forțele Terestre, în general, și structurile organice, în special, vor trebui să-și schimbe semnificativ mentalitatea operațională, planificând, pregătind și executând operațiile de o manieră hibridizată pentru a putea depăși un adversar accentuat hibridizat.

\section{NOTE:}

1 *** Army Regulation 350-2, Operational Environment and Opposing Force Program, Headquarters, Department of the Army, Washington DC, 19 May 2015, p. 1.

2 *** APP-28, Tactical Planning for Land Forces, Edition A, Version 1, NATO Standardization Office (NSO), November 2019, p. 2-19.

3 *** TM 2010-404, Intelligence Preparation of the Battlefield and Operational Environment-General Principles and Research Avenues, Defence R\&D Canada - Valcartier, November 2010, p. 21.

$4 * * *$ ATP 2-01.3, Intelligence Preparation of the Battlefield, Headquarters, Department of the Army, Washington DC, March 2019, p. 1-3.

5 Ibidem, p. 5-1.

6 Ibidem, pp. 5-2 - 5-3.

7 *** TRADOC G-2 ACE, Threat Tactics Report: Islamic State of Iraq and the Levant, version 1.6, February 2016, pp. 7-8.

8 *** Joint Publication (5-0), Joint Publications, Joint Force Development, 1 December 2020, p. GL-11.

9 Ibidem, p. GL-7.

10 *** APP-28, Tactical Planning for Land Forces, Edition A, Version 1, NATO Standardization Office (NSO), November 2019, p. 3-3.

$11 * * *$ ADRP 3-05, Special Operations, Headquarters, Department of the Army, Washington DC, January 2018, p. 1-9.

12 Ibidem, pp. 2-1 - 2-9.

$13 * * *$ JP 3-05, Special Operations, Joint Chiefs of Staff, July 2014, p. x.

\section{BIBLIOGRAFIE}

*** Army Regulation 350-2, Operational Environment and Opposing Force Program, Headquarters, Department of the Army, Washington, DC, 19 May 2015.

***APP-28, Tactical Planning for Land Forces, Edition A, Version 1, NATO Standardization Office (NSO), November 2019.

*** TM 2010-404, Intelligence Preparation of the Battlefield and Operational Environment General Principles and Research Avenues, Defence R\&D Canada - Valcartier, November 2010. 
*** ATP 2-01.3, Intelligence Preparation of the Battlefield, Headquarters, Department of the Army, Washington, DC, March 2019. *** TRADOC G-2ACE, Threat Tactics Report:

Islamic State of Iraq and the Levant, version 1.6, February 2016.
*** Joint Publication (5-0), Joint Publications, Joint Force Development, 1 December 2020.

*** ADRP 3-05, Special Operations, Headquarters, Department of the Army, Washington DC, January 2018.

*** JP 3-05, Special Operations, Joint Chiefs of Staff, July 2014. 